\begin{abstract}
Iranica
Abstracta Iranica Revue bibliographique pour le domaine irano-aryen

Volume 42-43 | 2021

Comptes rendus des publications de 2019-2020

\section{Francis Joannès. « La fin de Rēmūt-Ninurta, chef de la Maison Murašû »}

\title{
Olga Popova
}

\section{OpenEdition}

Journals

Édition électronique

URL : https://journals.openedition.org/abstractairanica/52387

DOI : 10.4000/abstractairanica.52387

ISSN : 1961-960X

Éditeur :

CNRS (UMR 7528 Mondes iraniens et indiens), Éditions de l'IFRI

Référence électronique

Olga Popova, «Francis Joannès. "La fin de Rēmūt-Ninurta, chef de la Maison Murašû » », Abstracta Iranica [En ligne], Volume 42-43 | 2021, document 23, mis en ligne le 15 avril 2021, consulté le 13 décembre 2022. URL : http://journals.openedition.org/abstractairanica/52387 ; DOI : https://doi.org/ 10.4000/abstractairanica.52387

Ce document a été généré automatiquement le 13 décembre 2022.

Tous droits réservés 
Francis Joannès. « La fin de RēmūtNinurta, chef de la Maison Murašû »

Olga Popova 


\section{RÉFÉRENCE}

Francis Joannès. " La fin de Rēmūt-Ninurta, chef de la Maison Murašû », ARTA 2020.003, [en ligne], p. 1-17. http://www.achemenet.com/pdf/arta/ARTA_2020_003.pdf

Dans cet article, F. Joannès étudie le dossier du séjour de Rēmūt-Ninurta, chef de la maison des Murašû, à Suse, en février-avril 417, et il émet l'hypothèse que la ruine de la famille Murašû a fait suite à ce voyage.

Un groupe de six textes de l'archive des Murašû relate le séjour de trois mois de RēmūtNinurta à Suse, la résidence royale des souverains achéménides. Lors de ce séjour, Rēmūt-Ninurta répond devant le tribunal royal à plusieurs accusations de perceptions indues des récoltes sur des terres qui ne lui appartenaient pas. F. Joannès complète ce dossier en faisant une réédition du texte $\mathrm{BE} 10118$, un procès contre la famille judéenne des fils de Țūb-Yāma, dont il localise la rédaction à Suse et non à Nippur. Il s'agit au total de trois affaires, deux procédures directes et une appellation, qui sont remontées jusqu'au roi à Suse. Rēmūt-Ninurta les perd toutes et est condamné à de lourdes sanctions financières.

3 Cela provoque, très probablement, une perte importante de prestige et de poids économique pour la firme des Murašû. De son retour à Nippur, Rēmūt-Ninurta participe de moins en moins aux affaires de la firme. L'année suivante, les affaires sont déjà régies par son neveu Enlil-šum-iddin et au printemps 416, l'archive des Murašû s'interrompt. Cela permet de considérer l'archive des Murašû comme une archive morte. F. Joannès fait le lien entre les condamnations du tribunal royal et l'effacement de Rēmūt-Ninurta des affaires, sa disparition en hiver 417-416 et l'arrêt de l'archive. Il suppose qu'ont eu lieu, non seulement un transfert des affaires de Rēmūt-Ninurta à son neveu, mais à plus long terme la ruine des entrepreneurs Murašû.

\section{AUTEURS}

\section{OLGA POPOVA}

Institute of Oriental Studies, Russian Academy of Sciences 